\title{
Pain Assessment Among Non-Communicating Intellectually Disabled People Described by Nursing Staff
}

\author{
Päivi Kankkunen*, Päivi Jänis and Katri Vehviläinen-Julkunen
}

Itä-Suomen Yliopisto, Kuopion Kampus, Hoitotieteen Laitos, PL 1627 70211, Kuopio, Finland

\begin{abstract}
The purpose of this study was to describe pain assessment among non-communicating intellectually disabled people living in long term care described by nursing staff. The target group of the study consisted of the nursing staff working at seven mental retardation units in different parts of Finland. The data were collected during spring 2008 by a semi-structured questionnaire (Non-communicating Children's Pain Checklist - Revised, N=222), and the response rate was $82 \%(n=181)$. The data were analyzed by statistical methods (Kruskall-Wallis test, Mann-Whitney U test) and by content analysis. The findings were described as parameters, frequencies, percentages, and as statistical significance.

The nursing staff considered their competence in identifying pain in non-communicating intellectually disabled people to be adequate, and they were of the opinion that enough attention is paid to pain. Almost all nursing staff assessed pain and the effect of treatment of pain on the basis of behavioural changes. Two thirds assessed the pain based on physiological changes. However, no pain assessment tools were used to assess pain and the effects of managing it. Two thirds of the staff considered the pain threshold to be high among non-communicating intellectually disabled people.

The findings of this study can be utilized in nursing practice and research, as well as in further education for pain assessment. Additional studies are needed to develop pain assessment to be more systematic among non-communicating intellectually disabled people.
\end{abstract}

Keywords: Intellectual disability, non-communicating, pain assessment, nursing staff.

\section{INTRODUCTION}

Intellectual disability is defined as mental retardation or impairment in the areas of development or cognitive activities [1]. Intellectual disability is "a disability characterized by significant limitations both in intellectual functioning and in adaptive behaviour, which covers many everyday social and practical skills. This disability originates before the age of 18 " [2],

In Finland, more than 50,000 people have been diagnosed as having intellectual disability. Because of intellectual disabilities many people are not able to express their pain verbally. Therefore, the skills of nursing staff are important to identify and manage pain in this vulnerable group of people.

Pain assessment and management have been the focus of interest internationally in several scientific fields. However, research into pain assessment among non-communicating intellectually disabled people has been very limited. The staff may have difficulties in interpreting the clients' behaviours [3], and pain among these clients may remain unidentified. Pain assessment among intellectually disabled people is usually very difficult [4-7] because of insufficient assessment methods and nurses' insufficient knowledge and education [8].

*Address correspondence to this author at the Itä-Suomen Yliopisto, Kuopion Kampus, Hoitotieteen Laitos, PL 1627 70211, Kuopio, Finland; Tel: 040-8211 984; E-mail: paivi.kankkunen@uef.fi
Pain assessment is essential among non-communicating intellectually disabled people. According to Stallard and coauthors (2001), intellectually disabled people suffer from pain often on a daily basis but their pain is not actively managed. Pain is mostly chronic [8] and, according to Hadden and Baeyer (2002), the duration of pain is between one to five hours with a mean intensity of 2.4 (scale 1-5).

Pain in non-communicating people can be assessed by observing physiological changes, such as breathing, skin colour $[5,8,10,11]$, sweating $[5,8,11]$, urinating, blood pressure and heart rate [12]. Additionally, pain can be assessed by observing behavioural changes [13]. Facial expressions and aggressive behaviour are common indicators of pain $[5,10,14]$. Vocal expressions and body posture may also indicate pain.

Pain can be assessed by using different types of pain assessment tools. Non-communicating intellectually disabled people are not usually able to use any self-rating scales and, therefore, their pain should be assessed by using observation scales. NCCPC-PV (non-communicating children's pain checklist-postoperative version) is developed to assess postoperative pain [15] and NCCPC-R [non-communicating children's pain checklist-Revised] is developed for parents to assess their child's pain $(8,9)$. NCCPC-PV, r-FLACC[revised-face, legs, activity, cry, consolability] and NAPI [nursing assessment of pain intensity] can be used by nurses and physicians [16]. Table 1 summarises pain assessment tools that can be used to assess pain in non-communicating intellectually disabled people. 
Table 1. Pain Assessment Tools that can be Used to Assess Pain in non-Communicating Intellectually Disabled People

\begin{tabular}{|l|l|}
\hline \multicolumn{1}{|c|}{ Pain Assessment Tool, Authors } & \multicolumn{1}{|c|}{ Description of Categories to be Observed } \\
\hline \hline $\begin{array}{l}\text { NCCPC-PV (non-communicating children's pain checklist, postoperative version) } \\
\text { Breau } \text { et al., 2002 }\end{array}$ & Vocal, social, facial, activity, body and limbs, physiological signs \\
\hline $\begin{array}{l}\text { NCCPC-R (non-communicating children's pain checklist-Revised) } \\
\text { Breau } \text { et al., 2003 }\end{array}$ & $\begin{array}{l}\text { Vocal, social, facial, activity, body and limbs, } \\
\text { physiological, eating/sleeping }\end{array}$ \\
\hline $\begin{array}{l}\text { r-FLACC (revised-face, legs, activity, cry, consolability) } \\
\text { Voepel-Lewis et al., 2008 }\end{array}$ & $\begin{array}{l}\text { Face expressions, leg position/movement, } \\
\text { activity, cry/vocal, consolability }\end{array}$ \\
\hline $\begin{array}{l}\text { NAPI (nursing assessment of pain intensity) } \\
\text { Voepel-Lewis et al., 2008 }\end{array}$ & \begin{tabular}{l} 
Verbal/vocal, body, movement, facial, response to touch \\
\hline
\end{tabular}
\end{tabular}

Documentation of pain management and its effectiveness is based on systematic use of a validated pain assessment tool. It is recommended that pain should be re-assessed 30 minutes after administration of analgesics [17]. The nurses should be able to use pain assessment tools and to evaluate how effective the method used in pain management was. Documentation of pain assessment and management provides the basis for continuity of care too [18].

The purpose of this study was to describe pain assessment among non-communicating intellectually disabled people living in long term care described by nursing staff. Research questions were the following:

1. How do nursing staff working in long term care identify pain in non-communicating intellectually disabled people?

2. How do nursing staff assess pain in noncommunicating intellectually disabled people?

3. How are nursing staff's background variables related to the assessment of pain in non-communicating intellectually disabled people?

\section{MATERIALS AND METHODOLOGY}

\section{Data and Methods}

The target group consisted of 222 nursing staff (here referred to as nurses) working at seven social welfare organisations for disabled people and who were taking care of non-communicating clients during spring 2008. Altogether 181 nurses completed the questionnaires with the response rate being $82 \%$. Head nurses distributed the questionnaires to their staff and the questionnaires were returned in pre-paid envelopes to the researcher.

Semi-structured questionnaires were used to collect the data. The questionnaire was pilot-tested with nine members of nursing staff and no need for changes was identified. The questionnaire consisted of nurses' background information, six variables measuring identification of pain in noncommunicating intellectually disabled people and the NCCPC-R (Non-communicating Children's Pain Checklist Revised) [15], including 31 variables measuring behavioural changes. This instrument was chosen because it includes categories e.g. changes in eating and sleeping which are important pain expressions among non-verbal persons. The questionnaire was translated into Finnish and back-translated into English by a bi-lingual language teacher at the University of Kuopio. During the translation process two variables were added to the instrument.
Identification of pain was measured using a five-point Likert scale $(1=$ totally agree, $2=$ partly agree, $3=$ do not know, $4=$ partly disagree, $5=$ totally disagree). The nurses were asked how often they observed the given behavioural changes in non-communicating intellectually disabled people (NCCPC-R). The scale was $1=$ very often, $2=$ often, $3=$ seldom, $4=$ very seldom and $5=$ never. The instrument measures behavioural changes in seven areas: vocal, social, facial, activity, body and limbs, physiological, and eating/sleeping. The data were analysed using SPSS for Windows 15.0 program. Frequencies, percentages, the Mann-Whitney U-test and Kurskall-Wallis test were used to analyse the data $[19,20]$.

\section{Description of the Participants}

Most of the participants were female and assistant or practical nurses. Their mean age was 45 years and almost half of them had been working in health care for more than 20 years and in the care of intellectually disabled people for more than 10 years. Eight percent of the nursing staff had undergone additional education for pain management (Table 2).

\section{RESULTS}

More than a fifth of the nurses stated that noncommunicating intellectually disabled people cannot feel or express pain. Almost all nurses considered behavioural changes as indicators of pain. Two thirds considered their clients' pain threshold to be high. One third of the nurses did not know if their clients had pain on a daily basis (Table $\mathbf{3}$ ). Twelve percent of the nurses had used a pain measurement tool to assess pain in their clients.

Most nurses assessed intellectually disabled people's pain based on vocal expressions, such as moaning, crying and screaming. Flinching or moving the body part away and being sensitive to touch were used as pain indicators by most nurses. More than half of the nurses assessed the client's pain based on changes in the client's social behaviour. Changes such as having less interaction with others and withdrawal were observed while assessing pain. Lack of contact and movements was used seldom in pain assessment (Table 4).

Nurses' background variables (gender, vocational education, age, working experience in health care, working experience with intellectually disabled, number of beds at the ward, additional education for pain management) were not related to their descriptions of identification and 
assessment of pain in intellectually disabled people (p-value higher than 0.05).

Table 2. Background Information of the Participants (\%)

\begin{tabular}{|c|c|}
\hline Background Information & $\%$ \\
\hline \multicolumn{2}{|l|}{ Gender $(n=181)$} \\
\hline Female & 95 \\
\hline Male & 5 \\
\hline \multicolumn{2}{|l|}{ Vocational Education $(\mathrm{n}=\mathbf{1 8 1})$} \\
\hline Nurse (RN) & 19 \\
\hline Assistant/practical nurse & 58 \\
\hline Other (e.g. head nurse) & 16 \\
\hline No formal education & 7 \\
\hline \multicolumn{2}{|l|}{ Age $(n=180)$} \\
\hline $19-25$ & 8 \\
\hline $26-35$ & 14 \\
\hline $36-45$ & 22 \\
\hline $46-55$ & 39 \\
\hline $56-63$ & 17 \\
\hline \multicolumn{2}{|c|}{ Working Experience in Health Care (Years) $(n=181)$} \\
\hline Less than 1 & 1 \\
\hline $1-5$ & 16 \\
\hline $6-10$ & 18 \\
\hline $11-20$ & 21 \\
\hline More than 20 & 44 \\
\hline \multicolumn{2}{|c|}{ Working Experience with Intellectually Disabled People (Years) $(n=179)$} \\
\hline Less than 1 & 6 \\
\hline $1-5$ & 24 \\
\hline $6-10$ & 19 \\
\hline $11-20$ & 16 \\
\hline More than 20 & 35 \\
\hline \multicolumn{2}{|l|}{ Number of Beds in the Ward $(n=180)$} \\
\hline Less than 10 & 9 \\
\hline $10-15$ & 21 \\
\hline $16-20$ & 12 \\
\hline $21-30$ & 49 \\
\hline More than 30 & 9 \\
\hline \multicolumn{2}{|c|}{ Additional Education for Pain Management (n=178) } \\
\hline No & 92 \\
\hline Yes & 8 \\
\hline
\end{tabular}

\section{DISCUSSION}

\section{Discussion of the Findings}

Only $8 \%$ of the nurses had undergone any additional education for pain management, even if they had long experience working with clients having intellectual impairment. It is essential to pay more attention to nurses' education in pain assessment because nurses should have skills to identify pain [17]. Earlier findings [7] have shown that clients with intellectual disabilities suffer from pain on a daily basis but their pain remains undertreated. For example, clients with AGU or INCL often have diseases causing pain and discomfort [21] and, therefore, it is essential that their pain is identified, assessed and managed. In this study, more than half of the nurses stated that their clients do not have pain on a daily basis. It is possible that pain among their clients is managed in an effective way. On the other hand, the nurses may lack skills to identify and assess the pain.

Almost all nurses assessed pain in their clients based on behavioural changes. Surprisingly, only one fifth of them assessed the pain based on client's crying. Earlier studies have shown $[9,11]$ that crying is a strong indicator of pain that should be notified in pain assessment. Additionally, facial changes were not considered as a pain indicator by almost half of the nurses, even if facial changes are described as an easy and simple indicator in pain assessment [22]. In this study, it is possible that clients with severe intellectual disabilities are not able to express their pain with facial expressions because many illnesses may cause rigidity in the client's face and facial expressions.

Only $2 \%$ of the nurses had often used a pain measurement tool to assess pain in their clients. It is possible that the nurses were not aware of the existing instruments, such as $\mathrm{r}-$

FLACC, NAPI and NCCPC-PV $[15,16]$, that have been published in English. Use of pain measurement instruments is essential for the evaluation of the effectiveness of pain management and continuity of care, and, therefore it is important to teach the nurses to use the instruments for assessment of pain in clients with intellectual disabilities. The instruments are easily accessed via the Internet, but it is obvious that they have not been translated into Finnish or validated with Finnish clients.

\section{Reliability of the Study}

The instrument was pilot-tested with nine nurses and no changes were made to it $[19,20]$. The original instrument has been found to be found to be valid and reliable [23]. The translated (Finnish version) was translated back into English and there was no need to revise the instrument. Internal consistency of the NCCPC-R measured with the sample of 181 nurses was high )Cronbach's alpha 0.81).

The nurses were given clear instructions how to fill in the questionnaire. The survey was national and because of a fairly high response rate $(82 \%)$ the results can be generalized to Finnish nurses working with clients having intellectual disabilities. Nursing research focusing on the care of clients having intellectual disabilities has been very limited in Finland and it is obvious that the nurses were very interested in this study and wanted to participate in it.

\section{Ethical Considerations}

Selection of the study topic was an ethical choice. Clients with intellectual disabilities are one of the vulnerable groups in health care and they have all the rights to receive effective pain assessment and management $[19,20]$. Participation in 
Table 3. Nurses' Descriptions of Identification of Pain in Non-Communicating Intellectually Disabled People (\%)

\begin{tabular}{|c|c|c|c|c|c|}
\hline Perception of Identification of Pain & $\begin{array}{l}\text { Totally } \\
\text { Agree }\end{array}$ & $\begin{array}{l}\text { Partly } \\
\text { Agree }\end{array}$ & Do Not Know & $\begin{array}{c}\text { Partly } \\
\text { Disagree }\end{array}$ & $\begin{array}{c}\text { Totally } \\
\text { Disagree }\end{array}$ \\
\hline Pain can be identified in client's behaviour $(\mathrm{n}=179)$ & 49 & 47 & 1 & 3 & 0 \\
\hline Relationship between the nurse and client has impact on identification of pain $(n=179)$ & 49 & 41 & 7 & 3 & 0 \\
\hline An intellectually disabled client can feel and express pain $(n=177)$ & 39 & 46 & 3 & 11 & 1 \\
\hline Pain can be identified as physiological changes $(n=177)$ & 19 & 59 & 17 & 5 & 0 \\
\hline Intellectually disabled clients have a high pain threshold $(\mathrm{n}=175)$ & 14 & 49 & 20 & 14 & 3 \\
\hline Intellectually disabled clients have pain on a daily basis $(n=178)$ & 2 & 8 & 34 & 42 & 14 \\
\hline
\end{tabular}

the study was voluntary and the nurses were given information about the study in a covering letter.

Each organisation gave approval for the study. In addition, the study was approved by the Ethical Board of Pääjärvi Municipal Federation (112/2008). Approval to use the NCCPC-R was provided by Lynn Breau, who is the developer of the instrument.

\section{CONCLUSIONS}

1. Nurses identify pain in their clients with intellectual disabilities by observing behavioural changes.

2. Nurses assess the pain mainly by observing moaning, whining, whimpering or flinching or moving the body part away, or being sensitive to touch.

Table 4. Nurses' Assessment of Pain in Intellectually Disabled People Based on Behavioural Changes (Non-Communicating Children's Pain Checklist - Revised, NCCPC-R) (\%)

\begin{tabular}{|c|c|c|c|c|c|}
\hline Behavioural Change & Very Often & Often & Seldom & Very Seldom & Never \\
\hline Moaning, whining, whimpering $(\mathrm{n}=179)$ & 42 & 42 & 12 & 3 & 1 \\
\hline Flinching or moving the body part away, being sensitive to touch $(\mathrm{n}=180)$ & 41 & 44 & 13 & 3 & 0 \\
\hline Protecting, favouring or guarding part of the body that hurts $(n=180)$ & 37 & 47 & 12 & 4 & 0 \\
\hline Screaming/yelling $(\mathrm{n}=178)$ & 28 & 50 & 19 & 3 & 0 \\
\hline Crying $(\mathrm{n}=178)$ & 27 & 39 & 26 & 6 & 2 \\
\hline Increase/decrease in sleep $(\mathrm{n}=180)$ & 25 & 51 & 17 & 6 & 1 \\
\hline Stiff, spastic, tense, rigid $(\mathrm{n}=179)$ & 23 & 51 & 20 & 4 & 1 \\
\hline Eating less, not interested in food $(\mathrm{n}=179)$ & 23 & 50 & 21 & 4 & 2 \\
\hline Sharp intake of breath, gasping $(\mathrm{n}=178)$ & 21 & 37 & 31 & 10 & 1 \\
\hline Not cooperating, cranky, irritable, unhappy $(\mathrm{n}=179)$ & 20 & 63 & 13 & 4 & 0 \\
\hline Change in colour, pallor $(\mathrm{n}=178)$ & 15 & 53 & 25 & 6 & 1 \\
\hline Sweating, perspiring $(\mathrm{n}=178)$ & 14 & 56 & 24 & 7 & 0 \\
\hline Tears $(\mathrm{n}=179)$ & 13 & 43 & 31 & 11 & 2 \\
\hline A furrowed brow $(\mathrm{n}=179)$ & 12 & 35 & 37 & 15 & 1 \\
\hline A change in eyes: squinting of eyes, eyes opened wide, eyes frowning ( $n=177)$ & 12 & 34 & 44 & 9 & 2 \\
\hline Turning down of mouth, not smiling $(\mathrm{n}=179)$ & 12 & 33 & 39 & 14 & 2 \\
\hline Being difficult to distract, not able to satisfy or pacify ( $\mathrm{n}=179$ ) & 11 & 48 & 35 & 6 & 0 \\
\hline Shivering $(\mathrm{n}=178)$ & 11 & 40 & 34 & 13 & 2 \\
\hline Jumping around, agitated, fidgety $(\mathrm{n}=179)$ & 11 & 31 & 36 & 15 & 8 \\
\hline Floppy $(n=179)$ & 11 & 24 & 47 & 15 & 3 \\
\hline Lips puckering up, tight, pouting, or quivering $(\mathrm{n}=179)$ & 8 & 28 & 42 & 17 & 4 \\
\hline Seeking comfort or physical closeness $(n=180)$ & 8 & 38 & 40 & 13 & 1 \\
\hline Less interaction with others, withdrawn $(\mathrm{n}=174)$ & 6 & 31 & 50 & 13 & 0 \\
\hline Not moving, less active, quiet $(\mathrm{n}=180)$ & 5 & 32 & 44 & 16 & 3 \\
\hline Clenching or grinding teeth, chewing or thrusting tongue out $(\mathrm{n}=178)$ & 4 & 15 & 47 & 25 & 9 \\
\hline
\end{tabular}


3. Pain assessment tools are very seldom used by the nurses.

Based on this study, it can be concluded that there is a need for additional education for the nurses in the area of pain assessment and management. It seems that pain in clients having intellectual disabilities is not assessed in an effective way and that nurses need additional education to use pain assessment tools. Professional nursing organizations could arrange this kind of education for their staff. Pain assessment and the use of different tools should also be included in nurses' basic education programs.

This study provided challenges for further research:

1. How do nurses utilize international pain assessment tools in nursing practice?

2. How could pain assessment among clients with intellectual disabilities be improved?

3. How is pain assessment of clients with intellectual disabilities taught in Finnish nurse education?

\section{REFERENCES}

[1] Kehitysvammalaki 519/1977 [Law of intellectual disabilities]. Available at: http://www.finlex.fi/fi/laki/alkup/1977/19770988

[2] American Association on Intellectual and Developmental Disabilities [AAIDD], 2009. http://www.aaidd.org/content_100. cfm?navID=21 [Accessed: November 17, 2009].

[3] Kaski M, Manninen P, Pihko H. Kehitysvammaisuus [Intellectual disability]. Helsinki: WSOY 2009.

[4] Abu-Saad HH. Challenge of pain in the cognitively impaired. Lancet 2000; 356: 1867-68

[5] Zwakhalen SMG, Van Dongen KAJ, Hamers JPH, Abu-Saad HH. Pain assessment in intellectually disabled people: non-verbal indicators. J Adv Nurs 2004; 45: 236-45.

[6] Malviya S, Voepel-Lewis T, Merkel S, Trait AR. Difficult pain assessment and lack of clinical knowledge are ongoing barriers to effective pain management in children with cognitive impairment. Acute Pain 2005; 7: 27-32.

[7] Stallard P, Williams L, Lenton S, Velleman R. Pain in cognitively impaired, non-communicating children. Arch Dis Child 2001; 85: 460-62.
[8] Breau LM, Camfield CS, McGrath PJ, Finley GA. The incidence of pain in children with severe cognitive impairments. Arch Ped Adolesc Med 2003; 157: 1219-26.

[9] Hadden KL, von Baeyer CL. Pain in children with cerebral palsy: common triggers and expressive behaviours. Pain 2002; 99: 281-8.

[10] Donovan J. Learning disability nurses' experiences of being with clients who may be in pain. J Adv Nurs 2002; 38: 458-66.

[11] Carter B, McArthur E, Cunliffe M. Dealing with uncertainty: Parental assessment of pain in their children with profound special needs. J Adv Nurs 2002; 38: 449-57.

[12] Halimaa S-L. Hoidetaanko keskoslasten kipua? Tutkimus hoitajien valmiuksista arvioida ja hoitaa keskoslasten kipua. [Is pain in preterm babies treated?] University of Kuopio, Department of Nursing Science, Doctoral dissertation. ISSN: 1235-0494; 2001.

[13] Kyrkou M. Health issues and quality of life in women with intellectual disability. J Intell Disabil Res 2005; 49: 770-2.

[14] Collis L, Moss J, Jutley J, Cornish K, Oliver C. Facial expression of affect in children with Cornelia de Lange syndrome. J Intellect Disabil Res 2008; 52: 207-15.

[15] Breau LM, Finley GA, McGrath PJ, Camfield CS. Validation of the non-communicating children's pain checklist-postoperative version. Anesthesiology 2002; 96: 528-35.

[16] Voepel-Lewis T, Malviya S, Tait AR, Merkel S, Foster R, Krane EJ. A comparison of the clinical utility of pain assessment tools for children with cognitive impairment. Pediatric Anesthesiology 2008; 106: 72-8.

[17] Salanterä S. Vaikeaa dementiaa sairastavan vanhuksen kivun arviointi [Assessment of pain in elderly with severe dementia] Kipuviesti 2006; 2: 39-40.

[18] Haapio M, Reen E, Salonen A. In Sailo E, Vartti A-M, Eds Kivunhoito [Nursing care of pain]. Tampere, Tammi 2000; 149-63.

[19] Burns N, Grove S. Understanding nursing research. $3^{\text {rd }}$ ed. Philadelphia: Saunders 2003.

[20] Kankkunen P, Vehviläinen-Julkunen K. Tutkimus hoitotieteessä [Research in nursing science]. ${ }^{\text {st }}$ ed. Juva: WSOYpro 2009.

[21] Hennequin M, Morin C, Feine JS. Pain expression and stimulus localisation in individuals with Down's syndrome. Lancet 2000; 356: $1882-87$.

[22] LaChapelle D, Hadjistavropoulos T, Craig K. Pain measurement in persons with intellectual disabilities. Clin J Pain 1999; 15: 13-23.

[23] Breau LM, Camfield CS, McGrath PJ, Finley GA. Risk factors for pain in children with severe cognitive impairments. Dev Med Child Neurol 2004; 46: 364-71.

This is an open access article licensed under the terms of the Creative Commons Attribution Non-Commercial License (http://creativecommons.org/licenses/by$\mathrm{nc} / 3.0 /$ ) which permits unrestricted, non-commercial use, distribution and reproduction in any medium, provided the work is properly cited. 